\title{
Allosteric Modulation of $\mathrm{GAB}_{\mathrm{AA}}$ Receptor Subtypes: Effects on Visual Recognition and Visuospatial Working Memory in Rhesus Monkeys
}

\author{
Paul L Soto*,', Nancy A Ator', Sundari K Rallapalli ${ }^{2}$, Poonam Biawat ${ }^{2}$, Terry Clayton ${ }^{3}$, \\ James M Cook ${ }^{2}$ and Michael R Weed' \\ 'Division of Behavioral Biology, Department of Psychiatry and Behavioral Sciences, Johns Hopkins School of Medicine, Baltimore, \\ MD, USA; ${ }^{2}$ Department of Chemistry and Biochemistry, University of Wisconsin Milwaukee, Milwaukee, WI, USA; ${ }^{3}$ Chromatic \\ Technologies, Colorado Springs, CO, USA
}

\begin{abstract}
Non-selective positive allosteric modulators (PAMs) of $G A B A_{A}$ receptors (GABA $R$ s) are known to impair anterograde memory. The role of the various $G A B A_{A} R$ subtypes in the memory-impairing effects of non-selective $G A B A_{A} R$ PAMs has not been fully elucidated. The current study assessed, in rhesus monkeys, effects of modulation of $\alpha 1, \alpha 2 / 3$, and $\alpha 5 G A B A_{A} R s$ on visual recognition and spatial working memory using delayed matching-to-sample (DMTS) and self-ordered spatial search (SOSS) procedures, respectively. The DMTS procedure $(n=8)$ involved selecting a previously presented 'sample' image from a set of multiple images presented after a delay. The SOSS procedure $(n=6)$ involved touching a number of boxes without repeats. The non-selective GABA $R$ PAM triazolam and the $\alpha I G A B A_{A}$ preferential PAMS zolpidem and zaleplon reduced accuracy in both procedures, whereas the $\alpha 5 G A B A_{A}$ preferential PAMs $\mathrm{SH}-053-2^{\prime} \mathrm{F}-\mathrm{R}-\mathrm{CH}_{3}$ and $\mathrm{SH}-053-2^{\prime} \mathrm{F}-\mathrm{S}-\mathrm{CH}_{3}$, and the $\alpha 2 / 3 \mathrm{GABA}$ A preferential PAM TPA023B were without effects on accuracy or trial completion. The low-efficacy $\alpha 5 G_{A B A} R$ negative allosteric modulator (NAM) PWZ-029 slightly increased only DMTS accuracy, whereas the high-efficacy $\alpha 5 G A B A_{A} R$ NAMs RY-23 and RY-24 did not affect accuracy under either procedure. Finally, the slopes of the accuracy dose-effect curves for triazolam, zolpidem, and zaleplon increased with box number in the SOSS procedure, but were equivalent across DMTS delays. The present results suggest that (I) $\alpha I G A B A_{A} R s$, compared with $\alpha 2 / 3$ and $\alpha 5 G A B A_{A} R s$, are primarily involved in the impairment, by non-selective $G A B A_{A} R$ PAMs, of visual recognition and visuospatial working memory in nonhuman primates; and (2) relative cognitive impairment produced by positive modulation of $G A B A_{A} R$ s increases with number of locations to be remembered, but not with the delay for remembering.

Neuropsychopharmacology (2013) 38, 23I5-2325; doi:I0.1038/npp.2013.137; published online 26 June 2013
\end{abstract}

Keywords: GABA A receptor; cognition; delayed-matching-to-sample; self-ordered spatial search; benzodiazepine; rhesus monkey

\section{INTRODUCTION}

Several clinically important effects of benzodiazepines (BZs), such as the anxiolytic, sedative, and muscle-relaxing effects, occur via positive allosteric modulation of $\mathrm{GABA}_{\mathrm{A}}$ receptors $\left(\mathrm{GABA}_{\mathrm{A}} \mathrm{Rs}\right)$. BZs also can produce anterograde memory impairment (Haefely et al, 1993), which is a useful effect when these drugs are used as adjuncts to surgical anesthesia, but problematic when the drugs are used for other indications (eg, Kleykamp et al, 2012; Mintzer and Griffiths, 1999b). The discovery of the heterogeneity of $\mathrm{GABA}_{\mathrm{A}} \mathrm{Rs}$, particularly those that contain $\mathrm{BZ}$ binding sites (ie, $\alpha 1-, \alpha 2-, \alpha 3-$, and $\alpha 5$-containing $\mathrm{GABA}_{\mathrm{A}} \mathrm{Rs}$ ), spurred

*Correspondence: Dr PL Soto, Division of Behavioral Biology, Department of Psychiatry and Behavioral Sciences, Johns Hopkins School of Medicine, 5510 Nathan Shock Drive, Suite. 3000, Baltimore, MD 2I224-6823, USA, Tel: 410550 2779, Fax: 410550 2780,

E-mail: psoto@jhmi.edu

Received 28 March 20 13; revised 21 May 20 13; accepted 21 May 20 I3; accepted article preview online 31 May 2013 research into the development of subtype-selective ligands that might produce clinically desired effects without unwanted side effects (Atack, 2011a, b; Ator et al, 2010; Clayton et al, 2007).

Of the BZ-sensitive GABA ${ }_{A} R$ subtypes, $\alpha 1-, \alpha 2 / 3$-, and $\alpha 5$ containing $\mathrm{GABA}_{\mathrm{A}}$ Rs have been implicated in cognition and memory. For example, mice with a point mutation in the gene coding for $\alpha 1 \mathrm{GABA}_{\mathrm{A}} \mathrm{Rs}$ were insensitive to the recallimpairing effects of the non-selective positive allosteric modulator (PAM) diazepam on passive avoidance and punishment of drinking (Rudolph et al, 1999). Also in mice, elimination of $\alpha 5 \mathrm{GABA}_{\mathrm{A}} \mathrm{Rs}$ improved water maze performance (Collinson et al, 2002) and mice with a point mutation in $\alpha 5 \mathrm{GABA}_{\mathrm{A}} \mathrm{Rs}$ displayed greater trace fear conditioning than wild-type mice (Crestani et al, 2002). In addition, in mice and rats, investigational drugs that are negative allosteric modulators (NAMs) at $\alpha 5 \mathrm{GABA}_{\mathrm{A}} \mathrm{Rs}$ improved performance and/or attenuated drug-induced deficits in a variety of preclinical memory assessments (Atack et al, 2006; Ballard et al, 2009; Chambers et al, 2003; 
Collinson et al, 2006; Dawson et al, 2006; DeLorey et al, 2001; Harris et al, 2008; Savic et al, 2008).

In contrast to the amount of work conducted on the role of $\mathrm{GABA}_{\mathrm{A}} \mathrm{R}$ subtypes in memory in rodents, relatively little work has been done on the role of $G_{A B A} R$ subtypes in memory in nonhuman or human primates. In one study, an $\alpha 5 \mathrm{GABA}_{\mathrm{A}} \mathrm{R}$ NAM Ro4938581 improved object retrieval and detour performance (ORD) in cynomolgus monkeys (Ballard et al, 2009); in another study, a low-efficacy $\alpha 2 / 3 \mathrm{GABA}_{\mathrm{A}} \mathrm{R}$ PAM TPA023 reversed ketamine-induced deficits on a spatial delayed-response task in rhesus monkeys (Castner et al, 2010). In rhesus monkeys, ORD deficits produced by the non-selective PAM triazolam and the $\alpha 1 \mathrm{GABA}_{\mathrm{A}} \mathrm{R}$-preferring zolpidem were blocked by an $\alpha 1 \mathrm{GABA}_{\mathrm{A}}$-preferring antagonist $\beta$-CCT, whereas an $\alpha 5 \mathrm{GABA}_{\mathrm{A}} \mathrm{R}$-preferring antagonist XLi-093 only blocked the triazolam-induced deficits (Makaron et al, 2013). Finally, in humans, the $\alpha 1 \mathrm{GABA}_{\mathrm{A}} \mathrm{R}$-preferring PAM zolpidem has produced an impairment in a variety of recall tasks (Kleykamp et al, 2012; Mintzer and Griffiths, 1999a,b).

No study has examined the effects of selective modulation of the various $\mathrm{GABA}_{\mathrm{A}} \mathrm{R}$ subtypes within a single study. The current study investigated the role of selective modulation of $\alpha 1, \alpha 2 / 3$, and $\alpha 5 \mathrm{GABA}_{\mathrm{A}} \mathrm{Rs}$ on visual recognition and visuospatial working memory in rhesus monkeys. The drugs tested (see Table 1) were a $\mathrm{GABA}_{\mathrm{A}}$ PAM with nonselective binding and efficacy (triazolam), two $\mathrm{GABA}_{\mathrm{A}}$ PAMs with selective binding affinity at $\alpha 1 G A_{B A} A_{A} R$ (zolpidem and zaleplon), a $\mathrm{GABA}_{\mathrm{A}} \mathrm{PAM}$ with selective efficacy at $\alpha 2, \alpha 3$, and $\alpha 5 \mathrm{GABA}_{\mathrm{A}} \mathrm{Rs}$ (TPA023B), two novel PAMs with preferential affinity and/or efficacy at $\alpha 5 \mathrm{GABA}_{\mathrm{A}} \mathrm{Rs}$ ( $\mathrm{SH}-053-2^{\prime} \mathrm{F}-\mathrm{R}-\mathrm{CH}_{3}$ and $\mathrm{SH}-053-2^{\prime} \mathrm{F}-\mathrm{S}-\mathrm{CH}_{3}$ ), and three NAMs with selective binding affinity and varying negative efficacies at $\alpha 5 \mathrm{GABA}_{\mathrm{A}} \mathrm{Rs}$ (PWZ-029, RY-23, and RY-24).

The behavioral procedures were selected from the Cambridge Neuropsychological Testing Automated Battery (CANTAB), which is a battery of tests that have been used extensively to study cognitive functioning in humans. Due to their non-verbal nature, CANTAB tests have been extended to nonhuman primates (Pearce et al, 1998; Roberts et al, 1990; Weed et al, 1999; Zurcher et al, 2010) and thereby allow direct cross-species comparisons. For the present study, a delayed matching-to-sample (DMTS) procedure, designed to measure visual recognition memory, and a self-ordered spatial search (SOSS) procedure, designed to measure visuospatial working memory, were used. DMTS and SOSS performances have been shown to be sensitive to mild cognitive impairment and Alzheimer's disease (Barbeau et al, 2004; Lange et al, 1995; Riekkinen et al, 1998; Sahakian et al, 1988), suggesting the clinical relevance of these procedures.

\section{MATERIALS AND METHODS}

\section{Subjects}

Adult male rhesus monkeys (Macaca mulatta, $n=14$ ), aged $11.8 \pm 4.10$ (mean $\pm \mathrm{SD})$ years at the start of these experiments,

Table I Reported Binding Affinities and Efficacies in Modulating GABA-Induced Ion Flow at GABA ${ }_{A} R$ Subtypes of the Modulators Used in the Current Study

\begin{tabular}{|c|c|c|c|c|c|c|}
\hline Drugs & Affinity or $\%$ modulation & $\alpha \mathbf{I}$ & $\alpha 2$ & $\alpha 3$ & $\alpha 5$ & Reference \\
\hline \multirow[t]{2}{*}{ Triazolam } & Affinity $\left(K_{i}, n M\right)$ & 0.41 & 0.32 & 1.5 & 0.42 & Smith et al (200I) \\
\hline & $\%$ Modulation at $3 \mu \mathrm{M}$ & 132 & 255 & 270 & 165 & Sanna et al (2002) \\
\hline \multirow[t]{2}{*}{ Zolpidem } & Affinity $\left(K_{i}, n M\right)$ & 29.6 & 160 & 380 & $>10,000$ & Savic et al (20।0) \\
\hline & $\%$ Modulation at 100 nM & 180 & 132 & 121 & NS & Savic et al (20I0) \\
\hline Zaleplon & Affinity $\left(K_{i}, n M\right)$ & 66 & 830 & 710 & 1780 & Dämgen and Lüddens (1999) \\
\hline \multirow[t]{2}{*}{ TPA023B } & Affinity $\left(K_{i}, n M\right)$ & 0.73 & 2.0 & 1.8 & 1.1 & Atack et al (20। I) \\
\hline & $\%$ Modulation $^{\mathrm{a}}$ & 4 & 43 & 67 & 45 & Atack et al (20। I) \\
\hline \multirow[t]{3}{*}{$\mathrm{SH}-053-\mathrm{R}-2^{\prime} \mathrm{F}-\mathrm{CH}_{3}$} & Affinity $\left(K_{i}, n M\right)$ & 759.1 & 948.2 & 768.8 & 95.2 & Fischer et al (20।0); Savic et al (20।0) \\
\hline & $\%$ Modulation at $100 \mathrm{nM}$ & |11 & 124 & 125 & 183 & Fischer et al (20।0) \\
\hline & $\%$ Modulation at I $\mu \mathrm{M}$ & 154 & 185 & 220 & 387 & Fischer et al (2010) \\
\hline \multirow{2}{*}{ PWZ-029 } & $\%$ Modulation at I $\mu \mathrm{M}$ & 114 & 105 & 118 & -20 & Savic et al (2008) \\
\hline & $\%$ Modulation at $10 \mu \mathrm{M}$ & 120 & 115 & 145 & -20 & Savic et al (2008) \\
\hline \multirow[t]{2}{*}{ RY-23 } & Affinity $\left(K_{i}, n M\right)$ & 197 & 143 & 255 & 2.61 & Liu et al (1996) \\
\hline & $\%$ Modulation $^{\mathrm{a}}$ & -37 & -50 & & -52 & June et al (200I) \\
\hline \multirow[t]{2}{*}{ RY-24 } & Affinity $\left(K_{i}, n M\right)$ & 26.9 & 26.3 & 18.7 & 0.4 & Liu et al (1996) \\
\hline & $\%$ Modulation at I $\mu \mathrm{M}$ & -31 & -20.7 & 0 & -40.4 & Harris et al (2008) \\
\hline
\end{tabular}

NS = nonsignificant change in current flow.

${ }^{a}$ Concentration not specified. 
were singly housed, each in one section of a four-cage housing unit. All caging units were housed in the same temperature- and humidity-controlled vivarium room. Lights were on from 0700 to 02100 hours. Weights ranged between an average of $12.2 \mathrm{~kg} \pm 1.28$ at the beginning of the study and $14.5 \mathrm{~kg} \pm 1.72$ at the end of the study $(\sim 3.8$ years). Quantities of primate diet (2050 Teklad Global 20\% Protein Primate Diet, Harlan Laboratories) fed once daily (139-208g) were sufficient to permit gradual weight increase over the study. In addition, the monkeys received a piece of fresh fruit or vegetables (eg, $1 / 2$ orange, $1 / 2$ apple, and so on) 5 days a week. Daily feeding occurred approximately $2 \mathrm{~h}$ after completion of behavioral testing. Water was available at all times.

\section{Apparatus}

Experimental sessions were conducted in the home cage using custom-built mobile devices as described previously (Weed et al, 2008). Briefly, each held a computer for the control of experimental events (CANTAB software; Lafayette Industries, Lafayette, IN) and two touchscreen monitors (Intellitouch, surface acoustic wave technology, ELO TouchSystems, Menlo Park, CA, USA), which allowed two monkeys to be tested simultaneously. A pellet dispenser (BRS/VLE, Laurel, MD, or Med Associates, St Albans, VT) was used for the delivery of $190-\mathrm{mg}$ food pellets (BioServ, Frenchtown, NJ).

\section{DMTS and SOSS Procedures}

Eight monkeys were trained on the DMTS procedure. Each session consisted of 24 trials with 8 trials at each of three delays $(2,30$, or $300 \mathrm{~s})$. The delay on each trial was selected randomly without replacement. Each trial began with presentation, on the center of the screen, of a pseudorandomly selected sample image from a set of 600 different images (Photo Clip Art 150000 by Hemera Technologies). A touch on the sample image within $30 \mathrm{~s}$ turned off the image and initiated the selected delay. After the delay, the original sample image and two other unique, randomly selected images were presented on three corners of the screen. A touch on the image that 'matched' the original sample image produced a food pellet, followed by a 5 -s period with the screen darkened. If the monkey did not touch the sample image within $30-\mathrm{s}$, did not touch one of the three choice images within $30 \mathrm{~s}$, or if the monkey touched one of the two 'non-matching' images, the trial ended without pellet delivery, followed by $10 \mathrm{~s}$ with the screen darkened. Sessions usually lasted about $45 \mathrm{~min}$ and were conducted Monday-Friday, starting at approximately 1000 or 1100 hours.

Six monkeys were trained on the SOSS procedure. Each session consisted of 54 trials, and each trial involved touchscreen presentation of a configuration of a number of small blue boxes within 16 possible screen locations (screen configured in a 4 by 4 array of possible locations). The number of boxes in the stimulus configuration varied among 2, 3, and 4 boxes (18 trials of each). Each nonrepeating touch on any of the boxes produced a food pellet. If the monkey made a repeat touch or failed to make a touch within 30-s of trial onset or from the time of the previous touch, the trial ended and a 9-s period followed, during which the screen remained blank and touching the screen produced no scheduled consequence, which was followed by a new trial. If the monkey touched all the boxes without repetition, the trial ended, was defined as correct, and was followed by $5 \mathrm{~s}$ with the screen darkened before the next trial. Sessions generally lasted about 15-20 min and were conducted Monday-Friday, starting at approximately 1000 or 1100 hours.

\section{Assessment of Drug Effects}

Drug test sessions usually occurred on Tuesdays and Fridays if subjects had completed at least 7 of 8 trials at each delay (DMTS group) or 16 of 18 trials at each number of boxes (SOSS group) in the preceding session. Drug vehicle administration usually occurred on Thursdays. Baseline (no treatment) sessions occurred on Mondays and Wednesdays. In the DMTS group, the order of testing was RY-23 i.m. (intramuscular ), triazolam i.m., PWZ-029 i.m., SH-053-2'F-R-CH3 i.m., RY-24 i.m., zolpidem i.m., RY23 p.o. (per os), PWZ-029 p.o., SH-053-2'F-S-CH3 p.o., TPA023B p.o., and zaleplon p.o. In the SOSS group, the order of testing was RY-23 i.m., triazolam i.m., PWZ-029 i.m., RY-24 i.m., zolpidem, RY-24 p.o. RY-23 p.o., zaleplon p.o., PWZ-029 p.o., and TPA023B p.o. Doses were studied in a pseudo-random order for each compound with the restriction that the highest two doses were studied after the other doses. Triazolam, zolpidem, SH-053-2' F- $\mathrm{R}-\mathrm{CH}_{3}$, PWZ-029, RY-23, and RY-24 were administered via i.m. injection in the thigh at a volume of $0.2-1.5 \mathrm{ml}$. PWZ-029, RY-23, and RY-24 also were tested orally (p.o.) to extend the dose range beyond that which was feasible via the i.m. route. Zaleplon, TPA023B, and SH-053-2'F-S- $\mathrm{CH}_{3}$ only were administered p.o. due to solubility limitations. Pretreatment times were $30 \mathrm{~min}$ for i.m. administration of triazolam, zolpidem, PWZ-029, RY-23, RY-24, and SH-053-2' F-R- $\mathrm{CH}_{3}$ based on preliminary data collected in a subset of monkeys. Oral administration of zaleplon, TPA023B, SH-053-2'F-S$\mathrm{CH}_{3}$, PWZ-029, RY-23, and RY-24 occurred 60 min before session start.

\section{Drugs}

PWZ-029 (methyl(8-chloro-5,6-dihydro-5-methyl-6-oxo4H-imidazo[1,5-a][1,4]benzodiazepine-3-yl) methyl ester; Zhang et al, 1995), RY-23 (tert-Butyl 8-[(trimethylsilyl)ethynyl]-5,6-dihydro-5-methyl-6-oxo-4H-imidazo[1,5-a] [1,4] benzodiazepine-3-carboxylate; Liu et al, 1996), RY-24 (tert-Butyl 8-ethynyl-5,6-dihydro-5methyl-6-oxo-4H-imidazo[1,5-a[1,4]benzodiazepine-3-carboxylate; Liu et al, 1996), and $\mathrm{SH}-053-2^{\prime} \mathrm{F}-\mathrm{R}-\mathrm{CH}_{3}$ ((S)-8-ethynyl-6-(2-fluorophenyl)-4methyl-4H-2,5,10b-triaz-benzo[3]azulene-3-carboxylic acid ethyl ester; Cook et al, 2009), and SH-053-2' F-S-CH $\mathrm{CH}_{3}(\mathrm{~S})-8$ ethynyl-6-(2-fluorophenyl)-4-methyl-4H-2,5,10b-triaz-benzo[3]azulene-3-carboxylic acid ethyl ester; Cook et al, 2009) were synthesized at the Department of Chemistry and Biochemistry, University of Wisconsin, Milwaukee, WI. For i.m. injection, PWZ-029, RY-23, RY-24, and SH-053-2'F-R$\mathrm{CH}_{3}$ were dissolved in $95 \% \mathrm{w} / \mathrm{v}$ ethanol, which was diluted with a 60:40 mixture of propylene glycol and 0.9\% saline to a final concentration of $10-20 \%$ ethanol and $90-80 \%$ 
propylene glycol/saline mixture (prepared fresh each day), depending on doses to be tested. Triazolam (Upjohn Pharmaceuticals, Kalamazoo, MI) was dissolved in propylene glycol at $2 \mathrm{mg} / \mathrm{ml}$ (stored for up to 2 months) and then diluted with sterile water on test days to achieve the desired concentration for injection (minimum dilution of $50 \%$ sterile water). Zolpidem tartrate (Research Biochemicals International, Natick, MA) was dissolved in $0.9 \%$ saline (solutions were stored for up to 2 weeks). Zaleplon (Wyeth-Ayerst Research, Princeton, NJ) and TPA023B (6,2'-difluoro-50-[3-(1-hydroxy-1-methylethyl)imidazo[1,2b] [1,2,4]triazin-7-yl]biphenyl-2-carbonitrile; Merck, Sharp, \& Dohme, Harlow, UK) only were administered orally due to solubility limitations.

For oral administration, monkeys were first habituated gradually, across days, to drinking a bitter solution consisting of increasing concentrations of quinine (up to $0.32 \mathrm{mg} / \mathrm{ml}$ ) in $60 \mathrm{ml}$ of Tang orange-drink solution off the tip of a $60-\mathrm{ml}$ syringe. Consuming the $60 \mathrm{ml}$ was followed immediately by the opportunity to drink $40 \mathrm{ml}$ of unadulterated Tang (adapted from Turkkan et al, 1989). Once the consumption of the $0.32 \mathrm{mg} / \mathrm{ml}$ quinine solution was reliable, drug doses were suspended, fresh each test day, in $60 \mathrm{ml}$ of a matrix of $1 \mathrm{~g} / \mathrm{l}$ of Bio-Serv Agent K (Frenchtown, NJ), prepared in a blender in water that was flavored with the Tang powder.

\section{Data Analysis}

For the DMTS procedure, the percentage of correct trials in the session was calculated for individual monkeys by dividing the total number of correct trials at each delay by the total number of trials completed at that delay. The percentage of trials completed at each delay was calculated by dividing number of trials completed by total trials possible. For the SOSS procedure, the percentage of correct trials for each configuration (2, 3, and 4 boxes) was calculated for individual monkeys for each session by dividing the number of trials correct (ie, all boxes touched) divided by the number of trials in which the monkey touched at least one box. The percentage of trials completed for each number of boxes was calculated by dividing the number of trials in which the monkey touched at least one box by the number of trials possible. If a monkey did not complete three or more trials at any particular delay (DMTS) or number of boxes (SOSS) in a session, the percentage of correct trials was not calculated for that monkey. Group averages for percentage of correct trials were calculated only if three or more monkeys met the individual trial completion criterion.

Two-way repeated-measures analysis of variance (ANOVA) was used to identify statistically significant effects of drug dose and task parameter (DMTS: delay; SOSS: box number). Percentages of correct trials and trials completed were converted to proportions and arcsine square root transformed to increase normality for statistical analysis (McDonald, 2009). Post-hoc comparisons using the Holm-Sidak method were conducted to compare performance in vehicle sessions with performance following drug administration.

For drugs that affected accuracy, accuracy values for individual subjects at each dose were calculated as a percentage of the average vehicle accuracy at each parameter value for each of the two procedures. A linear model was fitted to the descending portion of the doseresponse curve using log dose and the pooled individual subject data (Graphpad Prism version 5, Graphpad Software, San Diego, CA). Minimal effective doses (MED) for reducing accuracy were calculated from the linear model as the dose necessary to reduce accuracy by $15 \%$ of vehicle control. This value was selected because the drugs that significantly reduced accuracy all did so by $15 \%$ or more at each parameter. In order to facilitate comparison of potencies to reduce accuracy and trial completion, the same method was used to predict the dose required to reduce trial completion by $15 \%$. Because trial completion did not vary across delay or number of boxes, normalization was unnecessary.

\section{RESULTS}

\section{Control Sessions}

DMTS accuracy after vehicle administration was highest after delays of 2 and $30 \mathrm{~s}$ and lowest after delays of $300 \mathrm{~s}$ (Figure 1, top panels, points above V). The percentage of trials completed did not differ as a function of delay (Figure 1, bottom panels, points above V). Similarly, SOSS accuracy following vehicle administration declined as the number of boxes in the stimulus configuration increased from 2 to 4 (Figure 2, top panels, points above $\mathrm{V}$ ), whereas the percentage of SOSS trials completed did not differ as a function of the number of boxes (Figure 2, bottom panels, points above V).

PAMs: Triazolam, zolpidem, zaleplon, TPA023B, SH-053$2^{\prime} \mathrm{F}-\mathrm{R}-\mathrm{CH}_{3}$, and $\mathrm{SH}-053-2^{\prime} \mathrm{F}-\mathrm{S}-\mathrm{CH}_{3}$. The non-selective high-efficacy PAM triazolam and the high-efficacy $\alpha 1 G A-$ $\mathrm{BA}_{\mathrm{A}} \mathrm{R}$-preferential PAM zolpidem reduced accuracy of DMTS performance at all delays (Figure 1; $\mathrm{F}_{6,18}=12.8$, $P<0.001$ and $F_{5,25}=7.22, P<0.001$, respectively) with MED values of $0.004-0.012$ and $0.172-0.18 \mathrm{mg} / \mathrm{kg}$, respectively (Table 2). Zaleplon, another high-efficacy $\alpha 1 \mathrm{GABA}_{\mathrm{A}}$ R-preferential PAM also reduced overall DMTS accuracy (Figure 1; $\mathrm{F}_{6,24}=6.20, P<0.001$; main effect of $18 \mathrm{mg} / \mathrm{kg}$ ) with MED values of $\sim 4-20 \mathrm{mg} / \mathrm{kg}$ (Table 2). Triazolam dose dependently reduced the percentage of DMTS trials completed $\left(\mathrm{F}_{6,30}=10.5, P<0.001\right)$, whereas zolpidem and zaleplon did not (Figure 1). TPA023B, a PAM with nonselective affinity, but selective efficacy at $\alpha 2 / 3 \mathrm{GABA}_{\mathrm{A}} \mathrm{Rs}$, did not affect DMTS accuracy or trial completion (Figure 1). Finally, the two $\alpha 5 \mathrm{GABA}_{\mathrm{A}} \mathrm{R}$-preferential PAMs SH-053-2'FR- $\mathrm{CH}_{3}$ and $\mathrm{SH}-053-2^{\prime} \mathrm{F}-\mathrm{S}-\mathrm{CH}_{3}$ did not affect DMTS accuracy or trial completion (Table 3 ).

Triazolam, zolpidem, and zaleplon also dose dependently decreased SOSS accuracy (Figure 2; $\mathrm{F}_{7,35}=18.7, P<0.001$, $\mathrm{F}_{5,35}=7.88, P<0.001, \mathrm{~F}_{6,30}=5.30, P<0.001$, respectively). The lowest dose of zaleplon increased SOSS accuracy on four-box trials (Figure 2, top rightmost graph). MED values for decreasing SOSS accuracy were 0.002-0.022, 0.0980.162 , and $2.65-14.2 \mathrm{mg} / \mathrm{kg}$ for triazolam, zolpidem, and zaleplon, respectively (Table 2 ). Triazolam decreased SOSS trials completed (Figure 2; $\mathrm{F}_{7,35}=3.18, P=0.01$ ) on threeand four- but, not on two-box trials (post-hoc comparisons) 

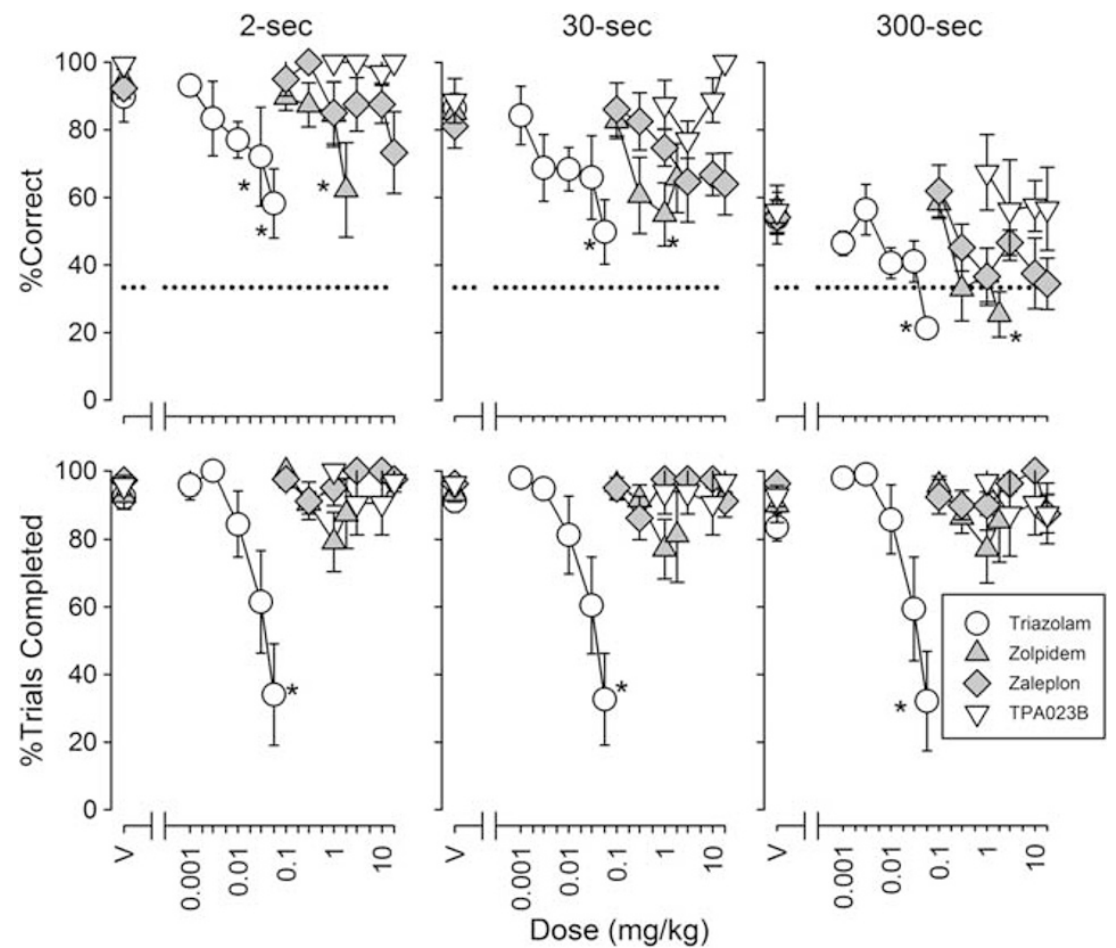

Figure I Effects of triazolam $(n=6)$, zolpidem $(n=6)$, zaleplon $(n=5)$, and TPA023B $(n=4)$ on accuracy (top row) and trial completions (bottom row) for trials at each delay value in the delayed matching-to-sample (DMTS) procedure. Points above ' $V$ ' represent results following vehicle administration. Each data point represents the mean across monkeys. Error bars represent \pm I SEM. The horizontal dashed line indicates a chance accuracy (33.3\%). Statistically significant post-hoc comparisons relative to vehicle are denoted by asterisks.

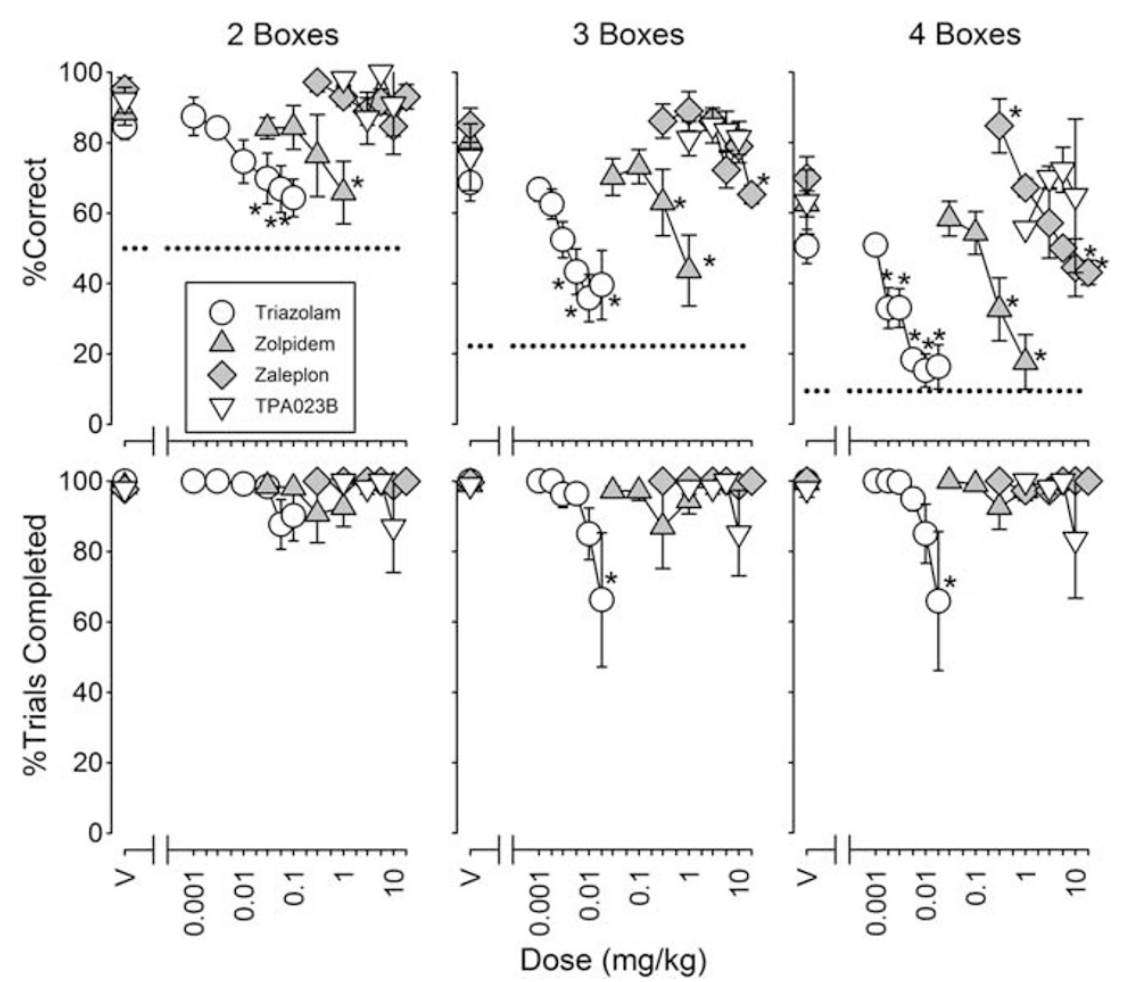

Figure 2 Effects of triazolam $(n=6)$, zolpidem $(n=6)$, zaleplon $(n=4)$, and TPA023B $(n=4)$ on self-ordered spatial search (SOSS) accuracy (top) and trial completion (bottom) for trials with each number of boxes in the SOSS procedure. The horizontal dotted lines in the top row of graphs represent chance accuracy on two-box (50\%), three-box (22.2\%), and four-box (9.38\%) trials. 
Table 2 MED Values (mg/kg) for Reducing Accuracy (Defined as 85\% of Vehicle Control Accuracy Values) and for Decreasing Trial Completion by the Same Amount for Each Drug that had Statistically Significant Effects on the Relevant-Dependent Measure

\begin{tabular}{|c|c|c|c|}
\hline \multirow[t]{2}{*}{ Drugs } & \multicolumn{3}{|c|}{ DMTS delays } \\
\hline & 2-s & $30-s$ & $300-s$ \\
\hline Triazolam i.m. & $0.012(0.003-0.613)$ & $0.004(0-0.023)$ & $0.004(0-0.016)$ \\
\hline Zolpidem i.m. & NS & $0.180(0-0.489)$ & $0.172(0.005-0.402)$ \\
\hline & \multicolumn{3}{|c|}{ Trial completion } \\
\hline Triazolam i.m. & $0.007(0.003-0.013)$ & $0.006(0.002-0.011)$ & $0.007(0.003-0.013)$ \\
\hline RY-23 p.o. & $1.75(0.294-3.064)$ & $1.62(0.182-2.919)$ & $1.22(0.014-2.493)$ \\
\hline RY-24 i.m. & $0.022(0.0 \mid$ I I-0.035) & $0.041(0.024-0.056)$ & $0.038(0.018-0.054)$ \\
\hline & \multicolumn{3}{|c|}{ Accuracy } \\
\hline Triazolam i.m. & $0.022(0.009-0.079)$ & $0.004(0.001-0.008)$ & $0.002(0.001-0.006)$ \\
\hline Zolpidem i.m. & NS & $0.162(0.004-0.358)$ & $0.098(0.012-0.188)$ \\
\hline \multirow[t]{2}{*}{ Zaleplon p.o } & NS & $14.2(5.70-194)$ & $2.65(1.53-4.37)$ \\
\hline & \multicolumn{3}{|c|}{ Trial completion } \\
\hline Triazolam i.m. & NS & $0.050\left({ }^{\mathrm{a}}-^{\mathrm{a}}\right)$ & $0.049\left({ }^{a}-^{a}\right)$ \\
\hline RY-24 i.m. & $0.048(0.024-0.069)$ & $0.049(0.025-0.070)$ & $0.048(0.024-0.070)$ \\
\hline RY-23 p.o. & $6.038(0.993-7.829)$ & $5.837(0-7.8 \mid I)$ & $5.954(0.46-7.777)$ \\
\hline RY-24 p.o. & $0.414\left({ }^{a}-^{a}\right)$ & $0.426\left({ }^{\mathrm{a}}-^{\mathrm{a}}\right)$ & $0.415\left({ }^{a}-{ }^{a}\right)$ \\
\hline
\end{tabular}

Abbreviations: DMTS, delayed matching-to-sample; i.m., intramuscular; p.o., per os; SOSS, self-ordered spatial search.

Numbers in parentheses are $95 \%$ confidence limits (CLs).

NS $=$ nonsignificant linear regression

${ }^{\mathrm{a}} 95 \% \mathrm{CL}$ could not be calculated.

with a potency of $\sim 0.05 \mathrm{mg} / \mathrm{kg}$. Zolpidem and zaleplon did not alter SOSS trial completion (Figure 2). TPA023B was without effect on SOSS accuracy and trial completion (Figure 2).

\section{Negative Allosteric Modulators: PWZ-029, RY-23, and RY-24}

The low-efficacy $\alpha 5 \mathrm{GABA}_{\mathrm{A}} \mathrm{R}$-selective NAM PWZ-029 (i.m.) produced a small, but statistically significant, improvement in performance (Figure $3 ; \mathrm{F}_{5,25}=3.72, \quad P=0.012$ ), but post-hoc tests did not reveal a dose at which the performance differed significantly from vehicle performance and when administered orally, PWZ-029 was without statistically significant effect on accuracy or trial completion (Figure 3). The high-efficacy $\alpha 5 \mathrm{GABA}_{\mathrm{A}} \mathrm{R}$-selective NAMs RY-23 (i.m. or p.o.) and RY-24 (i.m.) were without statistically significant effects on DMTS accuracy (Figure 3, top row). Trial completions at all delays were dose dependently decreased by i.m. RY-24 (Figure 3; $\mathrm{F}_{4,20}=7.34, P<0.001$ ) and p.o. RY$23\left(\mathrm{~F}_{5,10}=10.22, P=0.001\right)$, but not i.m. RY-23. The MED values of i.m. RY-24 and p.o. RY-23 in reducing trial completion were $0.022-0.041$ and $1.22-1.75 \mathrm{mg} / \mathrm{kg}$, respectively (Table 2).

In the SOSS procedure, RY-23 (i.m. and p.o.), RY-24 (i.m. and p.o.), and PWZ-029 (i.m. and p.o.) were without significant effects on accuracy (Figure 4), despite an apparent decreasing trend in accuracy with RY-24 (i.m.) on two- and three-box trials. Trial completions at all box numbers were decreased by RY-23 (p.o.) and RY-24 (i.m. and p.o.). Decreases in SOSS trial completion were statistically significant for p.o. RY-24 and p.o. RY-23 (Figure 4; $\mathrm{F}_{4,12}=4.65, P=0.017 ;$ and $\mathrm{F}_{4,16}=8.05, P<0.001$, respectively) and for i.m. RY-24 when the two subjects that were tested with the highest dose of $0.18 \mathrm{mg} / \mathrm{kg}$ were used in the ANOVA $\left(\mathrm{F}_{6,6}=17.1, P=0.002\right)$. (Only two monkeys were tested at $0.18 \mathrm{mg} / \mathrm{kg}$ because there was $\geqslant 50 \%$ suppression of trial completion at $0.1 \mathrm{mg} / \mathrm{kg}$ for the other monkeys, and we were concerned about adverse effects if we tested the higher dose in those monkeys.) MED values for reducing SOSS trial completion were $\sim 0.05,0.4$, and $0.6 \mathrm{mg} / \mathrm{kg}$ for RY-24 i.m., RY-24 p.o., and RY-23 p.o. (Table 2). 
Table 3 Percentage of Trials Correct and Completed After Administration of Vehicle (' $\mathrm{V}$ ') and Doses (mg/ $/ \mathrm{kg})$ of SH-053-2'F-S-CH $(n=4)$ and $\mathrm{SH}-053-2^{\prime} \mathrm{F}-\mathrm{R}-\mathrm{CH}_{3}(n=3)$ During DMTS Trials of 2-, 30-, and 300-s Delays

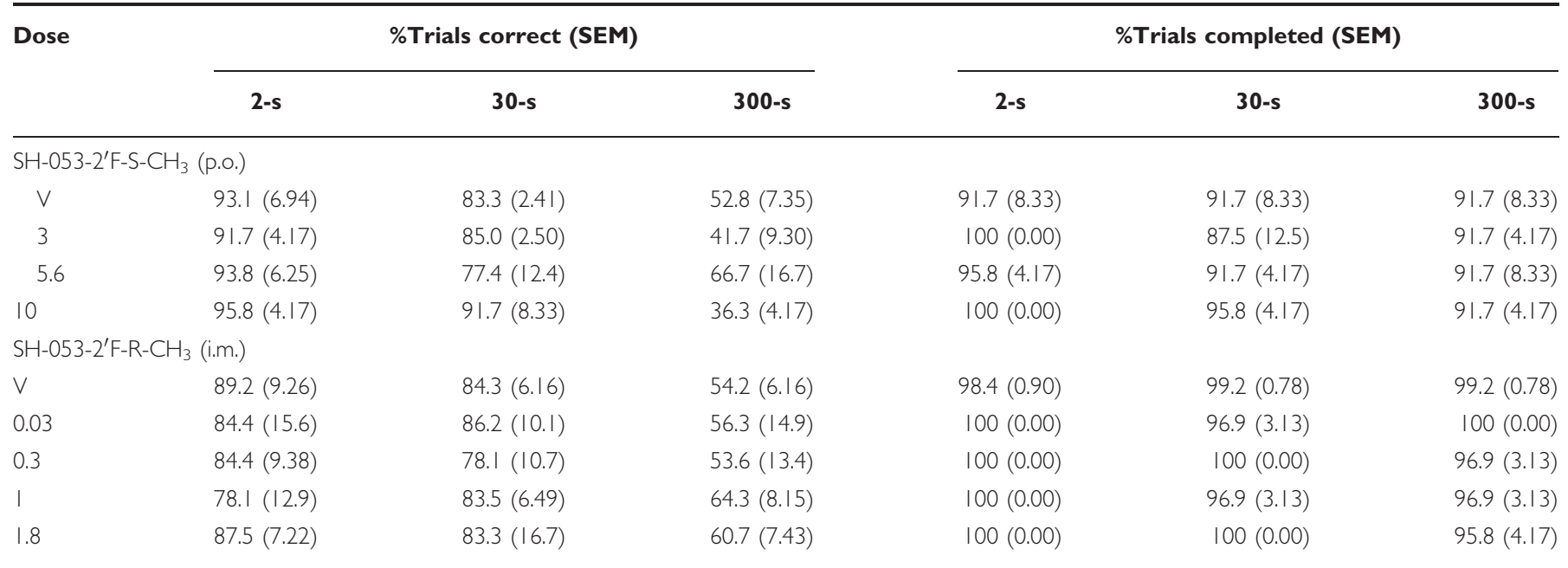

Abbreviations: DMTS, delayed matching-to-sample; i.m., intramuscular; p.o., per os.

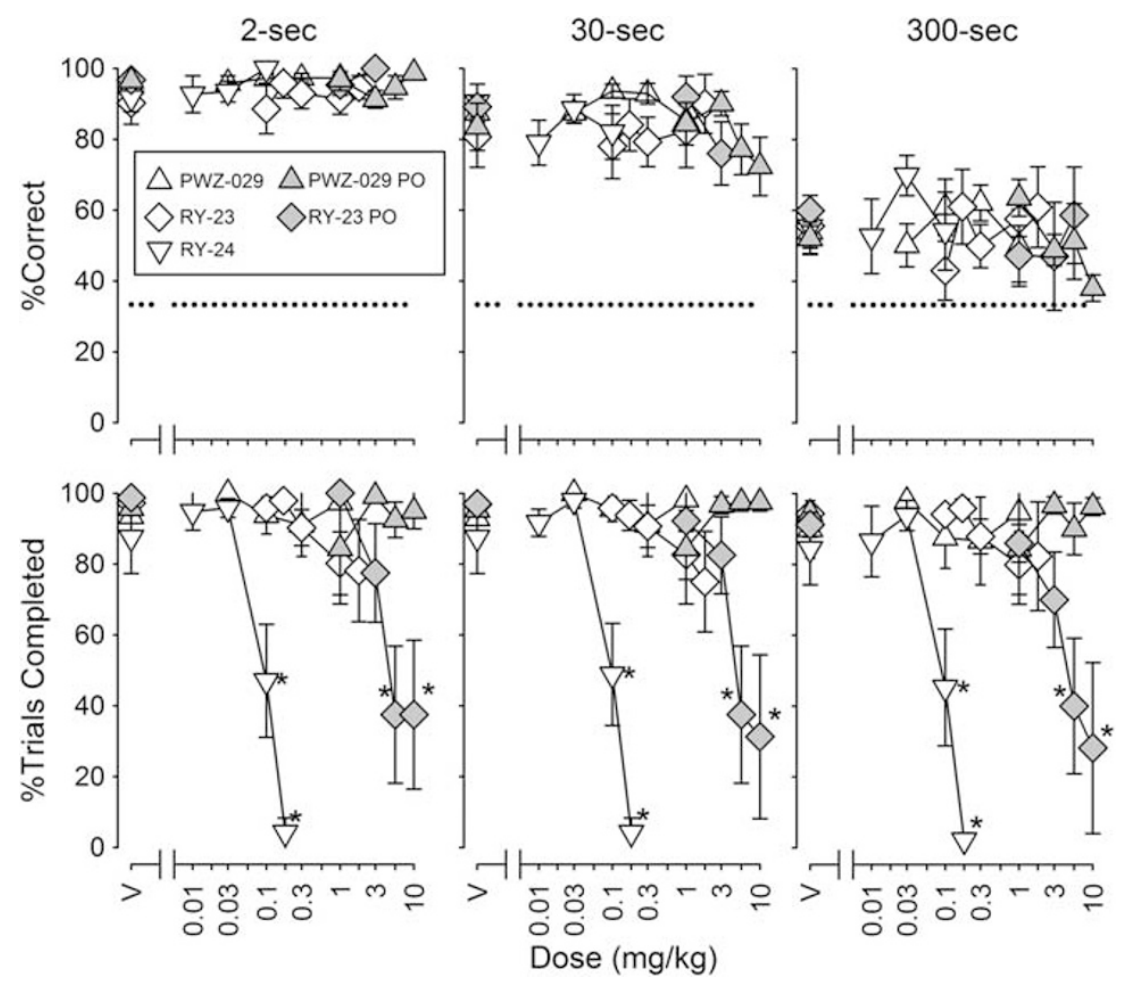

Figure 3 Effects of PWZ-029 i.m. (intramuscular) ( $n=7)$ and p.o. (per os) ( $n=5)$, RY-23 i.m. $(n=6)$ and p.o. $(n=5)$, and RY-24 i.m. ( $n=6)$ on delayed matching-to-sample (DMTS) accuracy (top) and trial completion (bottom). Other details are as in Figure I.

\section{Comparison of Effects of Triazolam, Zolpidem, and Zaleplon on DMTS and SOSS Performances}

For triazolam, zolpidem, and zaleplon, the relative impairment of accuracy did not depend on DMTS delay. The slopes of the dose-response curves for reducing DMTS accuracy at each delay value were not significantly different (Figure 5, top panels). In contrast, in the SOSS procedure, relative impairment of accuracy depended on the number of locations to be remembered. The slopes of the triazolam, zolpidem, and zaleplon dose-response curves varied sig- nificantly as number of boxes increased (Figure 5, bottom panels; $\mathrm{F}_{2,98}=4.83, P=0.01 ; \mathrm{F}_{2,66}=3.43, P=0.0384$; and $\mathrm{F}_{2,66}=12.3, P<0.001$, respectively).

\section{DISCUSSION}

The current results with triazolam are consistent with a number of studies demonstrating working memory impairment with other non-selective BZs in nonhuman primates (Baron and Wenger, 2001; Bradley and Nicholson, 1984; 

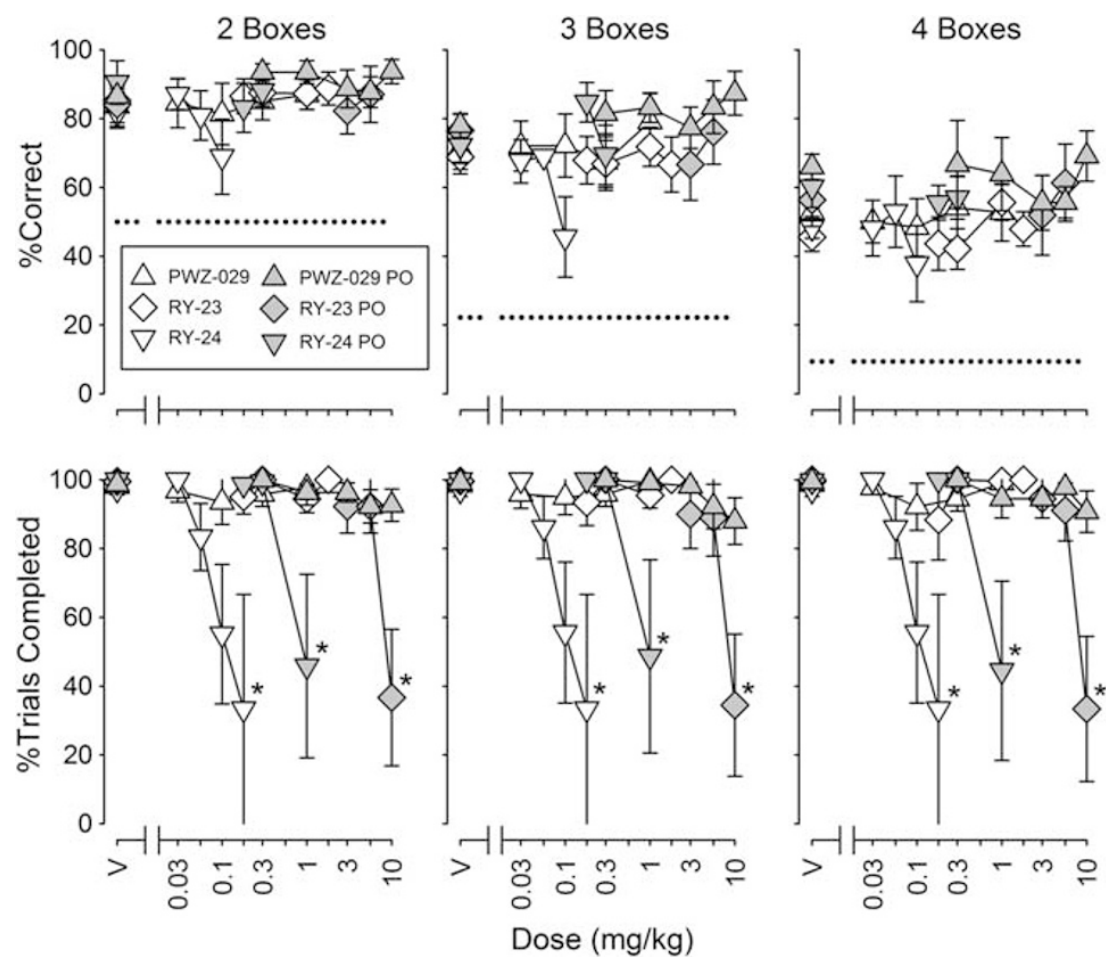

Figure 4 Effects of PWZ-029 i.m. $(n=6)$ and p.o. $(n=6)$, RY-23 i.m. $(n=6)$ and p.o. $(n=5)$, and RY-24 i.m. ( $n=6$ except that only two monkeys were tested at the highest dose as explained in Results) and p.o. $(n=4)$ on self-ordered spatial search (SOSS) accuracy (top) and trial completion (bottom). Other details are as in Figure 2.

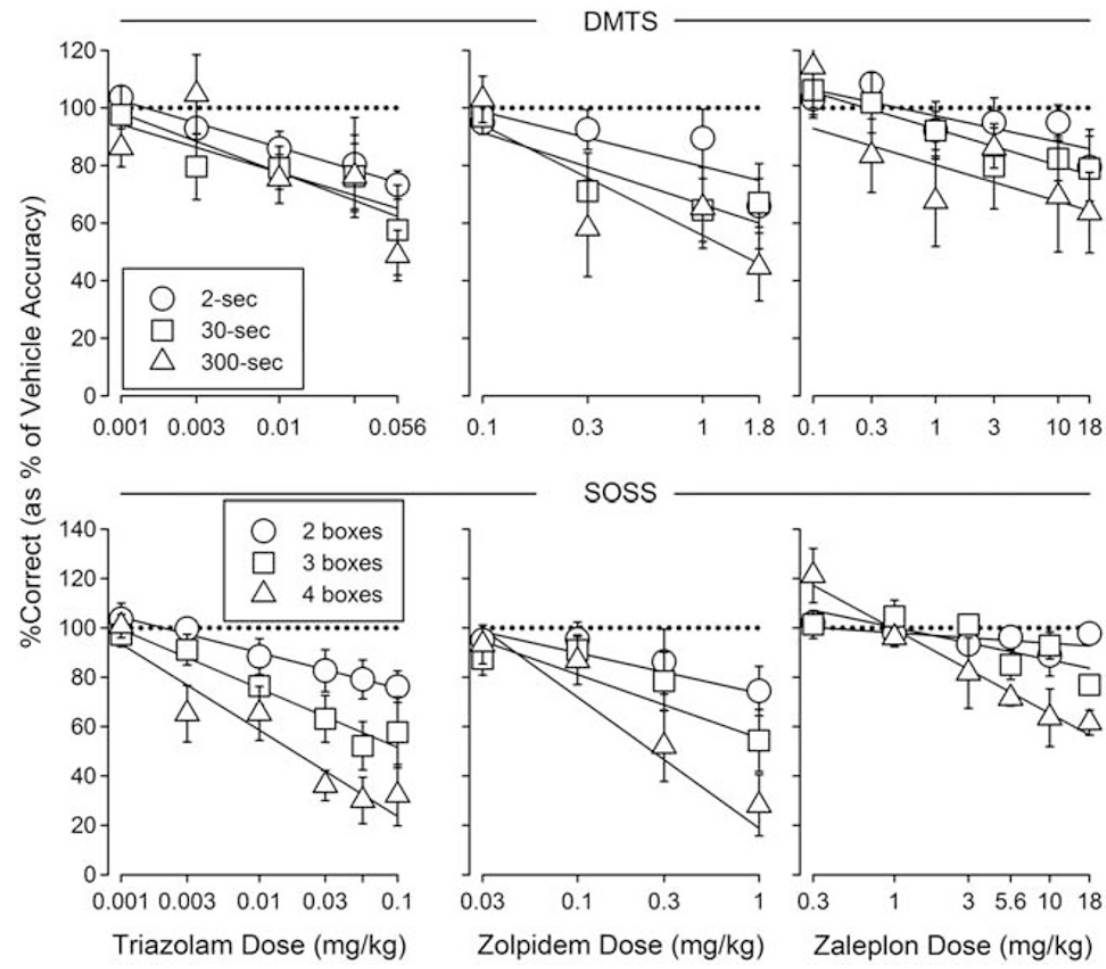

Figure 5 Normalized (\% of vehicle accuracy values) dose-response curves along with best-fitting straight lines for triazolam's (left), zolpidem's (middle), and zaleplon's (right) effects on delayed matching-to-sample (DMTS) (top) and self-ordered spatial search (SOSS) (bottom) accuracy. Each data point represents the mean across monkeys. Error bars represent \pm I SEM. The horizontal dotted lines are for reference and indicate I00\% of vehicle accuracy. Solid lines represent best-fitting lines. Other details are as in Figures I and 2 for DMTS and SOSS, respectively.

Myers and Hamilton, 2011; Schulze et al, 1989). Our results with subtype-selective $\mathrm{GABA}_{\mathrm{A}} \mathrm{R}$ PAMs suggest that modulation of $\alpha 1 \mathrm{GABA}_{\mathrm{A}} \mathrm{Rs}$, but not $\alpha 2 / 3$ or $\alpha 5 \mathrm{GABA}_{\mathrm{A}}$ Rs impairs visual recognition and visuospatial working memory in nonhuman primates; and, by extension, our results suggest that cognitive impairment produced by non-selective 
$\mathrm{GABA}_{\mathrm{A}} \mathrm{R}$ PAMs is primarily due to the modulation of $\alpha 1 \mathrm{GABA}_{\mathrm{A}} \mathrm{Rs}$. First and foremost, zolpidem, which has virtually no affinity for $\alpha 5 \mathrm{GABA}_{\mathrm{A}} \mathrm{Rs}$, and zaleplon, which has very low affinity for this subtype, produced dosedependent reductions in DMTS and SOSS accuracy, suggesting a lack of involvement of $\alpha 5 \mathrm{GABA}_{\mathrm{A}} \mathrm{Rs}$ in the effects of non-selective $\mathrm{GABA}_{\mathrm{A}} \mathrm{R}$ PAMs. Second, neither the $\alpha 5 \mathrm{GABA}_{\mathrm{A}} \mathrm{R}$-selective PAMs (SH-053-2' F-R- $\mathrm{CH}_{3}$ and $\mathrm{SH}-$ $053-2^{\prime} \mathrm{F}-\mathrm{S}-\mathrm{CH}_{3}$ ) nor the $\alpha 5 \mathrm{GABA}_{\mathrm{A}} \mathrm{R}$-selective NAMs (PWZ029, RY-23, and RY-24) affected DMTS or SOSS accuracy, even at doses of some of the NAMs that profoundly suppressed responding. Finally, the lack of effects of TPA023B, at $\mathrm{mg} / \mathrm{kg}$ doses shown to produce close to $100 \%$ occupancy of $\alpha 2 / 3 \mathrm{GABA}_{\mathrm{A}} \mathrm{Rs}$ in humans, baboons, rats, and mice (Atack et al, 2011), suggests that positive modulation of $\alpha 2 / 3 \mathrm{GABA}_{\mathrm{A}} \mathrm{Rs}$, at least at low levels, is not sufficient to produce impairments in visual recognition and visuospatial working memory. Interestingly, the lowest dose of zaleplon was associated with an improvement in SOSS accuracy on four-box trials, but this outcome was not shown with zolpidem, suggesting that such an improvement is not a general feature of low doses of non-selective or $\alpha 1 G A B A_{A} R$ preferential PAMs. Together, these results suggest that positive allosteric modulation of $\alpha 1 \mathrm{GABA}_{\mathrm{A}} \mathrm{Rs}$, compared with $\alpha 2 / 3$ and $\alpha 5 \mathrm{GABA}_{\mathrm{A}} \mathrm{Rs}$, is the major contributor to visual recognition and visuospatial working memory impairment produced by non-selective $\mathrm{GABA}_{\mathrm{A}} \mathrm{R}$ PAMs in nonhuman primates.

The lack of consistent, dose-dependent effects on DMTS and SOSS accuracy of the $\alpha 5 \mathrm{GABA}_{\mathrm{A}} \mathrm{R}$ NAMs is partially consistent with results in elderly human participants that demonstrated no effect in a paired-associates learning task at a low dose and impairment at a high dose of the $\alpha 5 \mathrm{GABA}_{\mathrm{A}} \mathrm{R}$ NAM $\alpha 5 \mathrm{IA}$ (Atack, 2010). The lack of robust effects of the $\alpha 5 \mathrm{GABA}_{\mathrm{A}} \mathrm{R}$ NAMs on DMTS and SOSS accuracy in the present study with rhesus monkeys do not appear consistent with results in rodents that demonstrated improved performance in Morris water maze and passive avoidance procedures with a variety of $\alpha 5 \mathrm{GABA}_{\mathrm{A}} \mathrm{R}$ NAMs (Atack et al, 2006; Chambers et al, 2003, 2004; Collinson et al, 2006; Savic et al, 2008). Nor are the present results consistent with those in cynomolgus monkeys that demonstrated improved ORD performance with an $\alpha 5 \mathrm{GABA}_{\mathrm{A}} \mathrm{R}$ NAM (Ballard et al, 2009). The variables responsible for these discrepancies are not clear, but may include both task and species. Perhaps the simplest explanation is that $\alpha 5 \mathrm{GABA}_{\mathrm{A}} \mathrm{R}$ NAMs do not have pro-cognitive effects on short-term working memory performances maintained by positive reinforcement. This conclusion is consistent with the current results as well as the lack of improvement with Ro4938591 on delayed matching-to-position performance in rats (Ballard et al, 2009) and the reported pro-cognitive effects on performance in the Morris water maze and untrained behavior such as passive avoidance behavior and ORD reaching. Importantly, PWZ-029 improved novel object recognition in rats without improving Morris water maze performance (Milic et al, 2013), demonstrating that $\alpha 5 \mathrm{GABA}_{\mathrm{A}} \mathrm{R}$ NAMs do not universally improve performance in aversively motivated working memory procedures such as the Morris water maze.

In addition, the failure of the $\alpha 5 \mathrm{GABA}_{\mathrm{A}} \mathrm{R}$ PAMs SH-053$2^{\prime} \mathrm{F}-\mathrm{R}-\mathrm{CH}_{3}$ and $\mathrm{SH}-053-2^{\prime} \mathrm{F}-\mathrm{S}-\mathrm{CH}_{3}$ to affect either DMTS or
SOSS performance is consistent with the results in rodents in which $\mathrm{SH}-053-2^{\prime} \mathrm{F}-\mathrm{R}-\mathrm{CH}_{3}$ was without effect on Morris water maze performance (Savic et al, 2010) and consistent with the failure of the $\alpha 5 \mathrm{GABA}_{\mathrm{A}} \mathrm{R}$ NAMs PWZ-029, RY-23, and RY-24 to alter DMTS or SOSS accuracy. Interestingly, a recent study demonstrated that an $\alpha 5 \mathrm{GABA}_{\mathrm{A}} \mathrm{R} P \mathrm{PAM}$ improved radial arm maze performance in aged impaired rats at doses that produced no change in the performance in young rats (Koh et al, 2012), which suggests that the effects of positive allosteric modulation of $\alpha 5 \mathrm{GABA}_{\mathrm{A}} \mathrm{Rs}$ may depend on the age of the subjects and/or the performance baseline.

The effects of zolpidem on DMTS accuracy compared with DMTS trial completion were more selective than those of triazolam. The ratios of the triazolam MED values for reducing accuracy and decreasing trial completion ranged from $\sim 0.6$ to 1.8. In contrast, zolpidem was without significant effects on trial completion at doses 10-fold greater than its MED value for reducing accuracy, indicating that the selectivity of zolpidem to reduce accuracy compared with trial completion was greater than that of triazolam. Whether the effects of zolpidem on accuracy and trial completion in the SOSS procedure were more selective than those of triazolam is unclear. The selectivity of triazolam for impairing SOSS accuracy compared with suppressing SOSS trial completion, based on ratios of MED values for the two measures $(\sim 13-25)$, was much higher than its selectivity in the DMTS procedure; a conservative estimate of the selectivity of zolpidem based on the highest dose tested $(1 \mathrm{mg} / \mathrm{kg})$ compared to its MED values for reducing SOSS accuracy $(0.098-0.162)$ suggests a selectivity within that range.

The reliability of the effects of $\mathrm{GABA}_{\mathrm{A}} \mathrm{R}$ PAMs and NAMs in the current study is demonstrated by the replication of effects across the two procedures and in the two groups of monkeys. Also, the current results demonstrate that degree of impairment produced by $\mathrm{GABA}_{\mathrm{A}} \mathrm{R}$ PAMs varied in a load-, but not delay-dependent fashion; relative impairment increased with the number of locations to be remembered in the SOSS procedure, but did not vary with the delay for remembering a stimulus in the DMTS procedure. The delayindependent effects of triazolam are consistent with studies reporting delay-independent impairment of DMTS performance by the non-selective $\mathrm{GABA}_{\mathrm{A}} \mathrm{R}$ PAM diazepam in humans and monkeys (Robbins et al, 1997; Schulze et al, 1989). The current study extends those findings to $\alpha 1$-selective $\mathrm{GABA}_{\mathrm{A}} \mathrm{R}$ PAMs. The differential sensitivity of SOSS, but not DMTS, performance to triazolam, zolpidem, and zaleplon is consistent with the notion that the two procedures measure different aspects of working memory and suggests that positive allosteric modulation of $\mathrm{GABA}_{\mathrm{A}} \mathrm{Rs}$ has a greater relative impact on spatial working memory as the number of locations to be remembered increases, but not on visual recognition working memory as the delay for remembering increases.

In conclusion, the present results suggest a prominent role of $\alpha 1 G A B A_{A} R s$ in the effects of non-selective $G_{A B A} R$ PAMs on visual recognition and visuospatial working memory in nonhuman primates. This finding implicates $\alpha 1 \mathrm{GABA}_{\mathrm{A}} \mathrm{Rs}$ in nonhuman primate working memory under unperturbed conditions; however, this conclusion is tentative given the risk associated with extrapolating from 
receptor function in perturbed (ie, drug-induced) conditions to receptor function in unperturbed conditions. The finding of a prominent role of $\alpha 1 \mathrm{GABA}_{\mathrm{A}} \mathrm{Rs}$ in the effects of non-selective $\mathrm{GABA}_{\mathrm{A}} \mathrm{R}$ PAMs on visual recognition and visuospatial working memory further suggests that the efforts to separate sedative and working memory-impairing effects of $\mathrm{GABA}_{\mathrm{A}} \mathrm{R}$ modulation may not be feasible because it appears that $\alpha 1 \mathrm{GABA}_{\mathrm{A}} \mathrm{Rs}$ are involved in both the sedative and memory-altering effects of drugs such as BZs. However, these studies suggest that positive modulators of $\alpha 2 / 3 \mathrm{GABA}_{\mathrm{A}} \mathrm{Rs}$, which have been pursued as non-sedating anxiolytics (eg, Atack, 2011a), would have minimal impact on cognitive function. The current results do not identify underlying brain regions or circuits involved in the effects of $\mathrm{GABA}_{\mathrm{A}} \mathrm{R}$ modulation on working memory, but future research might investigate local infusion of $G_{A B A} R$ modulators to determine brain region involvement. Future research also might investigate the effects of allosteric modulation of $\mathrm{GABA}_{\mathrm{A}} \mathrm{R}$ subtypes on visual recognition and visuospatial working memory in aged monkeys or in animals with neurobiological or pharmacological impairment to determine whether the effects vary as a function of age or state of impairment.

\section{FUNDING AND DISCLOSURE}

This work was supported by NIH grants R01-AG-027798 (NAA), R01-MH-046851 (JMC), and institutional funds of the Division of Behavioral Biology, Department of Psychiatry and Behavioral Sciences, The Johns Hopkins University School of Medicine. In the past 3 years, we have received compensation for professional services as follows: Dr Soto's work has been funded by the NIH and he has received compensation, unrelated to his scientific work, for database/software consulting from the Shands Hospital at the University of Florida. Dr Ator's work has been funded by the NIH and she has received funding from Helsinn Healthcare to conduct an abuse liability evaluation of an unrelated compound. Dr Ator also has received compensation from Bristol Myers-Squibb and F Hoffman LaRoche for consulting on abuse liability evaluation. Dr Rallapalli and Dr Biawat have received funding from the NIH. Dr Clayton is an employee of Chromatic Technologies. Chromatic Technologies. provided no financial support for these studies and had no scientific involvement. Dr Cook has received funding from NIH. Dr Cook currently holds patents on several of the compounds used in the current study. Dr Weed initiated these NIH-funded studies at Johns Hopkins School of Medicine before becoming an employee of Bristol Myers-Squibb. Upon leaving Johns Hopkins, direction of the studies was under the exclusive control of Drs. Ator and Soto. Bristol Myers-Squibb provided no financial support for these studies and had no scientific involvement.

\section{ACKNOWLEDGEMENTS}

We thank Stacey Perry, Raymond Smith, and Virginia Bogdan for their expert technical assistance in conducting these studies. We also thank Jonathan L Katz, Ph.D. for numerous helpful comments and discussions on the manuscript.

\section{REFERENCES}

Atack JR (2010). Preclinical and clinical pharmacology of the GABAA receptor alpha5 subtype-selective inverse agonist alpha5IA. Pharmacol Ther 125: 11-26.

Atack JR (2011a). GABAA receptor subtype-selective modulators. I. alpha2/alpha3-selective agonists as non-sedating anxiolytics. Curr Top Med Chem 11: 1176-1202.

Atack JR (2011b). GABAA receptor subtype-selective modulators. II. alpha5-selective inverse agonists for cognition enhancement. Curr Top Med Chem 11: 1203-1214.

Atack JR, Bayley PJ, Seabrook GR, Wafford KA, McKernan RM, Dawson GR (2006). L-655,708 enhances cognition in rats but is not proconvulsant at a dose selective for alpha5-containing GABAA receptors. Neuropharmacology 51: 1023-1029.

Atack JR, Hallett DJ, Tye S, Wafford KA, Ryan C, Sanabria-Bohorquez SM et al (2011). Preclinical and clinical pharmacology of TPA023B, a GABAA receptor \&alpha;2/ \&alpha;3 subtype-selective partial agonist. J Psychopharmacol 25: 329-344.

Ator NA, Atack JR, Hargreaves RJ, Burns HD, Dawson GR (2010). Reducing abuse liability of GABAA/benzodiazepine ligands via selective partial agonist efficacy at alpha1 and alpha2/3 subtypes. J Pharmacol Exp Ther 332: 4-16.

Ballard TM, Knoflach F, Prinssen E, Borroni E, Vivian JA, Basile $J$ et al (2009). RO4938581, a novel cognitive enhancer acting at GABAA alpha5 subunit-containing receptors. Psychopharmacology (Berl) 202: 207-223.

Barbeau E, Didic M, Tramoni E, Felician O, Joubert S, Sontheimer A et al (2004). Evaluation of visual recognition memory in MCI patients. Neurology 62: 1317-1322.

Baron SP, Wenger GR (2001). Effects of drugs of abuse on response accuracy and bias under a delayed matching-to-sample procedure in squirrel monkeys. Behav Pharmacol 12: 247-256.

Bradley CM, Nicholson AN (1984). Activity of the chloro- and triazolo-benzodiazepines. Behavioural studies in the monkey (Macaca mulatta). Neuropharmacology 23: 327-331.

Castner SA, Arriza JL, Roberts JC, Mrzljak L, Christian EP, Williams GV (2010). Reversal of ketamine-induced working memory impairments by the GABAAalpha2/3 agonist TPA023. Biol Psychiatry 67: 998-1001.

Chambers MS, Atack JR, Broughton HB, Collinson N, Cook S, Dawson GR et al (2003). Identification of a novel, selective GABA(A) alpha5 receptor inverse agonist which enhances cognition. J Med Chem 46: 2227-2240.

Chambers MS, Atack JR, Carling RW, Collinson N, Cook SM, Dawson GR et al (2004). An orally bioavailable, functionally selective inverse agonist at the benzodiazepine site of GABAA alpha5 receptors with cognition enhancing properties. J Med Chem 47: 5829-5832.

Clayton T, Chen JL, Ernst M, Richter L, Cromer BA, Morton CJ et al (2007). An updated unified pharmacophore model of the benzodiazepine binding site on gamma-aminobutyric acid(a) receptors: correlation with comparative models. Curr Med Chem 14: 2755-2775.

Collinson N, Atack JR, Laughton P, Dawson GR, Stephens DN (2006). An inverse agonist selective for alpha5 subunit-containing GABAA receptors improves encoding and recall but not consolidation in the Morris water maze. Psychopharmacology (Berl) 188: 619-628.

Collinson N, Kuenzi FM, Jarolimek W, Maubach KA, Cothliff R, Sur C et al (2002). Enhanced learning and memory and altered GABAergic synaptic transmission in mice lacking the alpha 5 subunit of the GABAA receptor. J Neurosci 22: 5572-5580.

Cook JM, Zhou H, Huang S, Sarma PVVS, Zhang C (2009): Stereospecific anxiolytic and anticonvulsant agents with reduced muscle-relaxant, sedative-hypnotic and ataxic effects. US Patent $7,681,958$. 
Crestani F, Keist R, Fritschy JM, Benke D, Vogt K, Prut L et al (2002). Trace fear conditioning involves hippocampal alpha5 GABA(A) receptors. Proc Natl Acad Sci USA 99: 8980-8985.

Dämgen K, Lüddens H (1999). Zaleplon displays a selectivity to recombinant GABAA receptors different from zolipdem, zopiclone and benzodiazepines. Neurosci Res Commun 25: 139-148.

Dawson GR, Maubach KA, Collinson N, Cobain M, Everitt BJ, MacLeod AM et al (2006). An inverse agonist selective for alpha5 subunit-containing GABAA receptors enhances cognition. J Pharmacol Exp Ther 316: 1335-1345.

DeLorey TM, Lin RC, McBrady B, He X, Cook JM, Lameh J et al (2001). Influence of benzodiazepine binding site ligands on fearconditioned contextual memory. Eur J Pharmacol 426: 45-54.

Fischer BD, Licata SC, Edwankar RV, Wang ZJ, Huang S, He X et al (2010). Anxiolytic-like effects of 8-acetylene imidazobenzodiazepines in a rhesus monkey conflict procedure. Neuropharmacology 59: 612-618.

Haefely WE, Martin JR, Richards JG, Schoch P (1993). The multiplicity of actions of benzodiazepine receptor ligands. Can J Psychiatry 38(Suppl 4): S102-S108.

Harris D, Clayton T, Cook J, Sahbaie P, Halliwell RF, Furtmuller R et al (2008). Selective influence on contextual memory: physiochemical properties associated with selectivity of benzodiazepine ligands at GABAA receptors containing the alpha5 subunit. J Med Chem 51: 3788-3803.

June HL, Harvey SC, Foster KL, McKay PF, Cummings R, Garcia M et al (2001). GABA(A) receptors containing (alpha) 5 subunits in the CA1 and CA3 hippocampal fields regulate ethanol-motivated behaviors: an extended ethanol reward circuitry. J Neurosci 21: 2166-2177.

Kleykamp BA, Griffiths RR, McCann UD, Smith MT, Mintzer MZ (2012). Acute effects of zolpidem extended-release on cognitive performance and sleep in healthy males after repeated nightly use. Exp Clin Psychopharmacol 20: 28-39.

Koh MT, Rosenzweig-Lipson S, Gallagher M (2012). Selective GABA(A) alpha5 positive allosteric modulators improve cognitive function in aged rats with memory impairment. Neuropharmacology 64: 145-152.

Lange KW, Sahakian BJ, Quinn NP, Marsden CD, Robbins TW (1995). Comparison of executive and visuospatial memory function in Huntington's disease and dementia of Alzheimer type matched for degree of dementia. J Neurol Neurosurg Psychiatry 58: 598-606.

Liu R, Hu RJ, Zhang P, Skolnick P, Cook JM (1996). Synthesis and pharmacological properties of novel 8-substituted imidazobenzodiazepines: high-affinity, selective probes for alpha 5-containing GABAA receptors. J Med Chem 39: 1928-1934.

Makaron L, Moran CA, Namjoshi O, Rallapalli S, Cook JM, Rowlett JK (2013). Cognition-impairing effects of benzodiazepine-type drugs: role of GABAA receptor subtypes in an executive function task in rhesus monkeys. Pharmacol Biochem Behav 104: 62-68.

McDonald JH (2009). Handbook of Biological Statistics. 2nd edn Sparky House Publishing: Baltimore, MD, USA.

Milic M, Timic T, Joksimovic S, Biawat P, Rallapalli S, Divljakovic J et al (2013). PWZ-029, an inverse agonist selective for alpha(5) GABAA receptors, improves object recognition, but not watermaze memory in normal and scopolamine-treated rats. Behav Brain Res 241: 206-213.

Mintzer MZ, Griffiths RR (1999a). Selective effects of zolpidem on human memory functions. J Psychopharmacol 13: 18-31.

Mintzer MZ, Griffiths RR (1999b). Triazolam and zolpidem: effects on human memory and attentional processes. Psychopharmacology (Berl) 144: 8-19.

Myers TM, Hamilton LR (2011). Delayed match-to-sample performance in African green monkeys (Chlorocebus aethiops sabaeus): effects of benzodiazepine, cholinergic, and anticholinergic drugs. Behav Pharmacol 22: 814-823.
Pearce PC, Crofts HS, Muggleton NG, Scott EA (1998). Concurrent monitoring of EEG and performance in the common marmoset: a methodological approach. Physiol Behav 63: 591-599.

Riekkinen M, Soininen H, Riekkinen P Sr, Kuikka J, Laakso M, Helkala EL et al (1998). Tetrahydroaminoacridine improves the recency effect in Alzheimer's disease. Neuroscience 83: 471-479.

Robbins TW, Semple J, Kumar R, Truman MI, Shorter J, Ferraro A et al (1997). Effects of scopolamine on delayed-matching-tosample and paired associates tests of visual memory and learning in human subjects: comparison with diazepam and implications for dementia. Psychopharmacology (Berl) 134: 95-106.

Roberts AC, Robbins TW, Everitt BJ, Jones GH, Sirkia TE, Wilkinson J et al (1990). The effects of excitotoxic lesions of the basal forebrain on the acquisition, retention and serial reversal of visual discriminations in marmosets. Neuroscience 34: 311-329.

Rudolph U, Crestani F, Benke D, Brunig I, Benson JA, Fritschy JM et al (1999). Benzodiazepine actions mediated by specific gamma-aminobutyric acid(A) receptor subtypes. Nature 401: 796-800.

Sahakian BJ, Morris RG, Evenden JL, Heald A, Levy R, Philpot M et al (1988). A comparative study of visuospatial memory and learning in Alzheimer-type dementia and Parkinson's disease. Brain 111, )Pt 3): 695-718.

Sanna E, Busonero F, Talani G, Carta M, Massa F, Peis M et al (2002). Comparison of the effects of zaleplon, zolpidem, and triazolam at various $\mathrm{GABA}(\mathrm{A})$ receptor subtypes. Eur $J$ Pharmacol 451: 103-110.

Savic MM, Clayton T, Furtmuller R, Gavrilovic I, Samardzic J, Savic S et al (2008). PWZ-029, a compound with moderate inverse agonist functional selectivity at $\mathrm{GABA}(\mathrm{A})$ receptors containing alpha5 subunits, improves passive, but not active, avoidance learning in rats. Brain Res 1208: 150-159.

Savic MM, Majumder S, Huang S, Edwankar RV, Furtmuller R, Joksimovic $S$ et al (2010). Novel positive allosteric modulators of GABAA receptors: do subtle differences in activity at alpha1 plus alpha5 versus alpha2 plus alpha3 subunits account for dissimilarities in behavioral effects in rats? Prog Neuropsychopharmacol Biol Psychiatry 34: 376-386.

Schulze GE, Slikker W Jr., Paule MG (1989). Multiple behavioral effects of diazepam in rhesus monkeys. Pharmacol Biochem Behav 34: 29-35.

Smith AJ, Alder L, Silk J, Adkins C, Fletcher AE, Scales T et al (2001). Effect of alpha subunit on allosteric modulation of ion channel function in stably expressed human recombinant gamma-aminobutyric acid(A) receptors determined using (36) Cl ion flux. Mol Pharmacol 59: 1108-1118.

Turkkan JS, Ator NA, Brady JV, Craven KA (1989). Beyond chronic catheterization in laboratory primates. In: Segal EF (ed). Housing, Care and Psychological Wellbeing of Captive and Laboratory Primates. Noyes Publications: Park Ridge, NJ, USA, pp 305-324.

Weed MR, Bryant R, Perry S (2008). Cognitive development in macaques: attentional set-shifting in juvenile and adult rhesus monkeys. Neuroscience 157: 22-28.

Weed MR, Taffe MA, Polis I, Roberts AC, Robbins TW, Koob GF et al (1999). Performance norms for a rhesus monkey neuropsychological testing battery: acquisition and long-term performance. Brain Res Cogn Brain Res 8: 185-201.

Zhang P, Zhang W, Liu R, Harris B, Skolnick P, Cook JM (1995). Synthesis of novel imidazobenzodiazepines as probes of the pharmacophore for 'diazepam-insensitive' GABAA receptors. J Med Chem 38: 1679-1688.

Zurcher NR, Rodriguez JS, Jenkins SL, Keenan K, Bartlett TQ, McDonald TJ et al (2010). Performance of juvenile baboons on neuropsychological tests assessing associative learning, motivation and attention. J Neurosci Methods 188: 219-225. 